\title{
CAPIVARA (Hydrochoerus hydrochaeris, LINNAEUS 1766) NA PAISAGEM URBANA DE CURITIBA-PR
}

\author{
Ariádina Maria Tonetti ${ }^{1}$, Daniela Biondi ${ }^{1}$, Julio Cesar de Moura Leite ${ }^{2}$ \\ ${ }^{1}$ Universidade Federal do Paraná, Curitiba, Paraná, Brasil, ariadinatonetti@gmail.com.br \\ ${ }^{1}$ Universidade Federal do Paraná, Curitiba, Paraná, Brasil, dbiondi@ufpr.br \\ ${ }^{2}$ Pontifícia Universidade Católica do Paraná, Curitiba, Paraná, Brasil, julio.leite@ pucpr.br
}

Recebido para publicação: 01/12/2016 - Aceito para publicação: 13/06/2017

\begin{abstract}
Resumo
Hydrochoerus hydrochaeris encontrou nas cidades brasileiras ambientes que dão suporte a sua sobrevivência. Isso se deve, entre outros fatores, a capacidade adaptativa e características biológicas desse grande roedor nativo. Como Curitiba é uma dessas cidades, objetivou-se investigar as características das paisagens das áreas verdes públicas com potencial de hábitat para a espécie. Sendo assim, foi realizado o estudo da paisagem e das populações de capivara em nove bosques e 22 parques públicos. A coleta dos dados paisagísticos ocorreu a partir de imagem de satélite e de dados vetoriais processados no Arcgis 10, considerando os componentes paisagísticos do interior da área (água, floresta, gramado, infraestrutura e rua) e do entorno (água, vegetação e área impermeável). Quanto à espécie animal, foram coletadas informações de ocorrência, abundância e composição de grupo, a partir de censos totais realizados entre agosto de 2013 e junho de 2015. A presença da capivara foi relacionada aos componentes da paisagem por meio da aplicação dos testes U de MannWhitney, Qui-quadrado e exato de Fisher. Os resultados indicaram que as capivaras estão presentes nas maiores áreas verdes, onde há quantidades maiores de recurso (água: 26,5\%, gramado: $23,3 \%$ e floresta: $33,5 \%)$, presença de ilha e rio e entornos com maiores áreas de vegetação e água. Indicou também, diferenças na forma como a espécie utiliza essas áreas, alguns parques são hábitats permanentes e outros são temporários. Os parques de uso permanente são maiores e apresentam maior quantidade de água (área média: $797.000 \mathrm{~m}^{2}$; água: 38,5\%) que os de uso temporário (área média: $152.000 \mathrm{~m}^{2}$; água: 14,6\%).

Palavras-chave: Fauna; ecologia; áreas verdes públicas.
\end{abstract}

\begin{abstract}
Capybara in the urban landscape, Curitiba-Pr. Hydrochoerus hydrochaeris has found in Brazilian cities environments that support their survival. This is due to, among other factors, the adaptive capacity and biological characteristics of this native large rodent. As Curitiba is one of those cities, this research aimed to investigate the characteristics of the landscape of public green areas with potential habitat for the species. Thus, it was conducted the landscape and capybara populations study in nine woodlands and 22 public parks. The landscape data was collected from vector data and satellite image processed in Arcgis 10, considering the landscape components from inside the area (water, forest, lawn, infrastructure and roads) and the surroundings (water, vegetation and impermeable area). About animal species, total census were conducted between August 2013 and June 2015 to collect occurrence data, abundance and group composition. The presence of the capybara was related to landscape components through the application of tests U MannWhitney, Chi-square and Fisher Exact. The results indicated that capybaras are present in the largest green areas, where there are larger amounts of resources (water: $26.5 \%$, grassland: $23.3 \%$ and forest: $33.5 \%$ ), island and river presence and environments with Greater areas of vegetation and water. He also indicated differences in the way the species uses these areas, some parks are permanent habitats and others are temporary. The permanent use parks are larger and have a greater amount of water (average area: $797.000 \mathrm{~m}^{2}$, water: $38.5 \%$ ) than those for temporary use (average area: $152.000 \mathrm{~m}^{2}$, water: $14.6 \%$ ).

Keywords: Fauna; ecology; public green areas.
\end{abstract}

\section{INTRODUÇÃO}

Muitas são as formas e propósitos de se estudar uma paisagem, na ecologia da paisagem o objetivo é entender as relações entre padrões espaciais e processos ecológicos, sendo necessário para isso quantificar os padrões espaciais (METZGER, 2006). Nesse sentido, o Sistema de Informação Geográfica (SIG) é uma ferramenta bastante utilizada nessa quantificação, por meio dela pode-se determinar o nicho de uma espécie, por exemplo, ao identificar as características bióticas e/ou abióticas de uma região (ALMEIDA et al., 2014).

FLORESTA, Curitiba, PR, v. 47, n. 3, p. 257 - 267, jul. / set. 2017.

Tonetti, A. M. et al.

ISSN eletrônico 1982-4688

DOI: $10.5380 /$ rf.v47i1.49821 
A maioria dos estudos relacionados à fauna visa à conservação de espécies silvestre. De acordo com Bolós (1992), pesquisam-se as espécies mais significativas (bioindicadoras), pois isso possibilita identificar o grau de naturalidade da paisagem. Estuda-se também a densidade populacional, uma vez que essa informa sobre a abundância, riqueza, adaptabilidade e possível influência das espécies sobre a paisagem. Ainda, entre outros, investiga-se sobre o endemismo, a singularidade e o valor especial, com cunho específico de interesse para a conservação de determinadas espécies animais ou vegetais.

Esses estudos, muitas vezes, estão apoiados na teoria de biogeografia de ilhas e nas teorias de metapopulações, que de acordo com Lang e Blaschke (2009) abordam a composição e distribuição dos elementos da paisagem (matriz, mancha/fragmento e corredor). A estrutura desses elementos na paisagem exerce vários efeitos sobre a fauna, especialmente na dinâmica das populações, na densidade populacional, na distribuição e mobilidade dessas na paisagem (LANG; BLASCHKE, 2009).

Em virtude da redução e fragmentação de grande parte dos hábitats naturais, os aglomerados urbanos tornaram-se possíveis nichos para a fauna silvestre. Curitiba é um desses centros urbanos onde a vida selvagem pode ser observada com facilidade nas áreas verdes da cidade. Entre as espécies, que tem se beneficiado com as ações humanas (sinantropismo) está a capivara (Hydrochoerus hydrochaeris), que é um roedor de grande porte cuja ocorrência abrange quase toda a América do Sul, sendo o Chile o único país sul-americano no qual a espécies não está presente. No Brasil é encontrada em todos os estados, ausente apenas em algumas regiões da caatinga nordestina, onde é considerada quase extinta (MOREIRA, et al., 2013). A capivara é um herbívoro semiaquático que vive em áreas abertas sob a influência de água e seus hábitats incluem vegetação ripária, savanas sazonalmente inundáveis e várzeas. Devido à perda de hábitat, a características biológicas e a resiliência esse mamífero pode ser encontrado também em corpos de água dentro dos limites urbanos, em parques públicos e áreas particulares (MOREIRA, et al., 2013; TONETTI; BIONDI, 2015).

Diante dessa realidade, a floresta urbana tornou-se uma opção de vida para esse mamífero, à medida que os fragmentos florestais urbanos disponibilizam ambientes nos quais a espécies pode encontrar água, alimento e abrigo. O mosaico de vegetação formado por esses fragmentos e a presença de rios conectores compõem uma estrutura espacial que possibilita a ocupação de populações de capivara em diferentes áreas dentro da paisagem urbana.

Nesse cenário, e com intuito de contribuir para a conservação de espécies silvestres em meio urbano, essa pesquisa teve o objetivo de estudar as paisagens de bosques e parques de Curitiba com potencial de hábitat para a capivara.

\section{MATERIAL E MÉTODOS}

Esta pesquisa foi desenvolvida em 31 áreas verdes (nove bosques e 22 parques) pertencentes à cidade de Curitiba, Paraná, cujo marco zero localiza-se nas coordenadas $25^{\circ} 25^{\prime} 40^{\prime \prime} \mathrm{S}$ e $49^{\circ} 16^{\prime} 23^{\prime \prime}$ W. Essas áreas foram selecionadas por apresentarem água (lago ou rio) em seus limites, critério estabelecido pelo fato da capivara ser uma espécie semiaquática cuja ocorrência abrange áreas úmidas e alagáveis (MOREIRA et al., 2013).

Com a finalidade de coletar dados de ocorrência, abundância e composição de grupo de Hydrochoerus hydrochaeris, foram realizados quatro censos totais em cada área verde (1 ${ }^{\circ}$ : Ago a Nov/2013; $2^{\circ}$ : Mar a Jun/2014; 3: Ago a Nov/2014; 4: Mar a Jun/2015). As visitas ocorreram no período da manhã (8 às 12 horas) e da tarde (13 às 17 horas). Caminhou-se por toda a extensão dos bosques e parques em busca da visualização e contagem dos animais. Quando as capivaras foram avistadas, permaneceu-se por trinta minutos observando a composição do(s) grupo(s) (número de grupo e quantidade de indivíduos por grupo). Por não ter sido utilizado método de marcação que auxiliasse na diferenciação dos animais e sabendo que os grupos de capivaras se organizam e se deslocam como unidades coesas (HERRERA, 2013), os grupos foram reconhecidos pela distância entre os aglomerados de capivaras. Nessa fase, foi utilizado o método de observação naturalística grupo focal (LEHNER, 1996).

Para estabelecer uma relação entre a paisagem das áreas verdes e o mamífero, foi realizada a caracterização da cobertura do solo de cada bosque e parque por meio dos métodos direto e indireto do estudo da paisagem, baseado em Almeida e Biondi (2011). Desta forma, foram confeccionados dados vetoriais dos componentes da paisagem (água, floresta, gramado, infraestrutura e rua) a partir de arquivos vetoriais obtidos com a Secretaria Municipal do Meio Ambiente (SMMA) e Instituto de Pesquisa e Planejamento Urbano de Curitiba (IPPUC). Com auxílio do programa ArcGis 10, os arquivos vetoriais obtidos com SMMA e IPPUC foram atualizados por meio da digitalização de informações complementares através da sobreposição com imagens do Satélite GeoEye-1 (resolução espacial $0,5 \mathrm{~m}$ ). As imagens utilizadas foram fornecidas pelo Laboratório de Paisagismo da Universidade Federal do Paraná e processadas por Grise et al. (2016).

Para compreender a influência do entorno sob a capivara, foi criado um buffer de 150 metros ao redor de cada área e os componentes da paisagem água, vegetação e área impermeável foram vetorizados, também no programa ArcGis 10 . 
No programa gratuito R, foram aplicados os testes U de Mann-Whitney e Exato de Fisher ( $p>5 \%)$, para avaliar se algum componente da paisagem ou o tamanho da área influenciam na ocorrência de capivara.

Por fim, foi confeccionado um mapa com o intuito de obter informações sobre a utilização de Hydrochoerus hydrochaeris nas áreas estudadas. As áreas com registros nas quatro campanhas de campo foram consideradas como de uso permanente e as áreas com registros em uma, duas ou três campanhas foram consideradas como de uso temporário. A paisagem dessas áreas, bem como seus entornos, foram analisados como descrito anteriormente.

\section{RESULTADOS}

As médias dos componentes da paisagem dos bosques correspondem a: 3,7\% de água, 13,3\% de gramado, 64,6\% de floresta, $10,0 \%$ de infraestrutura e 8,5\% de rua. Já as médias dos parques são representadas por: $18,4 \%$ de água, $25,4 \%$ de gramado, $38,7 \%$ de floresta, $12,0 \%$ de infraestrutura e $5,6 \%$ de rua. A capivara foi registrada apenas em parques (Tabela 1).

Tabela 1. Área e porcentagem das variáveis estudadas no interior dos bosques e parques de Curitiba (PR).

Table 1. Area and percentage of variables from inside the green areas of Curitiba (PR).

\begin{tabular}{|c|c|c|c|c|c|c|c|c|c|c|c|}
\hline \multirow{2}{*}{ Área Verde } & \multicolumn{2}{|l|}{ Água } & \multicolumn{2}{|c|}{ Gramado } & \multicolumn{2}{|c|}{ Floresta } & \multicolumn{2}{|c|}{ Infraestrutura } & \multicolumn{2}{|l|}{ Rua } & \multirow{2}{*}{$\begin{array}{c}\text { Total } \\
\mathbf{m}^{2} \\
\end{array}$} \\
\hline & $\mathbf{m}^{2}$ & $\%$ & $\mathbf{m}^{2}$ & $\%$ & $\mathbf{m}^{2}$ & $\%$ & $\mathbf{m}^{2}$ & $\%$ & $\mathbf{m}^{2}$ & $\%$ & \\
\hline \multicolumn{12}{|l|}{ Bosque } \\
\hline Alemão & 968 & 2,0 & 7.489 & 15,8 & 28.183 & 59,4 & 5.324 & 11,2 & 5.517 & 11,6 & 47.481 \\
\hline De Portugal & 893 & 3,1 & 1.185 & 4,1 & 15.908 & 55,4 & 4.083 & 14,2 & 6.656 & 23,2 & 28.725 \\
\hline Do Pilarzinho & 413 & 1,1 & 10.512 & 27,1 & 18.340 & 47,2 & 4.195 & 10,8 & 5.391 & 13,9 & 38.851 \\
\hline Do Trabalhador & 620 & 0,5 & 14.414 & 10,8 & 107.305 & 80,7 & 6.701 & 5,0 & 3.907 & 2,9 & 132.947 \\
\hline Irmã Clementina & 3.647 & 13,3 & 2.896 & 10,5 & 15.986 & 58,2 & 2.622 & 9,5 & 2.316 & 8,4 & 27.467 \\
\hline João Paulo II & 2.544 & 3,9 & 7.546 & 11,5 & 46.130 & 70,3 & 7.597 & 11,6 & 1.794 & 2,7 & 65.611 \\
\hline Reinhard Maack & 136 & 0,1 & 5.087 & 4,6 & 99.736 & 89,4 & 1.904 & 1,7 & 4.724 & 4,2 & 111.587 \\
\hline São Nicolau & 315 & 1,3 & 7.178 & 30,3 & 10.803 & 45,6 & 3.584 & 15,1 & 1.830 & 7,7 & 23.710 \\
\hline Zaninelli-Unilivre & 3.155 & 7,8 & 2.058 & 5,1 & 30.307 & 74,8 & 4.378 & 10,8 & 594 & 1,5 & 40.492 \\
\hline Média & 1.410 & 3,7 & 6.485 & 13,3 & 41.411 & 64,6 & 4.488 & $\mathbf{1 0 , 0}$ & 3.637 & 8,5 & $\mathbf{5 7 . 4 3 0}$ \\
\hline \multicolumn{12}{|l|}{ Parque } \\
\hline Atuba $^{1}$ & 18.562 & 12,3 & 57.194 & 37,8 & 52.253 & 34,5 & 16.156 & 10,7 & 7.127 & 4,7 & 151.292 \\
\hline Barigui $^{2}$ & 285.040 & 18,8 & 320.911 & 21,2 & 692.935 & 45,8 & 179.443 & 11,9 & 35.868 & 2,4 & 1.514 .197 \\
\hline Barreirinha & 5.872 & 4,5 & 5.302 & 4,1 & 108.978 & 83,8 & 9.155 & 7,0 & 695 & 0,5 & 130.002 \\
\hline Caiuá & 153 & 0,2 & 27.870 & 41,9 & 14.135 & 21,2 & 10.779 & 16,2 & 13.646 & 20,5 & 66.583 \\
\hline Cambuí ${ }^{2}$ & 21.007 & 13,5 & 41.452 & 26,7 & 71.518 & 46,1 & 13.305 & 8,6 & 7.939 & 5,1 & 155.221 \\
\hline Cent. Imigr. Japonesa $^{2}$ & 261.099 & 57,7 & 105.896 & 23,4 & 43.572 & 9,6 & 32.367 & 7,2 & 9.401 & 2,1 & 452.335 \\
\hline Das Pedreiras $^{1}$ & 8172 & 7,8 & 16.673 & 16,0 & 42.511 & 40,8 & 32.321 & 31,0 & 4.566 & 4,4 & 104.243 \\
\hline Diadema & 783 & 0,5 & 55.591 & 36,9 & 74.888 & 49,7 & 4.221 & 2,8 & 15.110 & 10,0 & 150.593 \\
\hline Dos Tropeiros & 411 & 0,2 & 83.940 & 44,8 & 52.490 & 28,0 & 42.838 & 22,9 & 7.490 & 4,0 & 187.169 \\
\hline Iberê de Mattos & 30.215 & 21,4 & 51.811 & 36,7 & 31.900 & 22,6 & 23.610 & 16,7 & 3.637 & 2,6 & 141.173 \\
\hline Italiano & 1288 & 1,1 & 36.560 & 29,9 & 76.356 & 62,5 & 4.773 & 3,9 & 3.139 & 2,6 & 122.116 \\
\hline Jardim Botânico & 8344 & 3,9 & 59.030 & 27,4 & 104.451 & 48,5 & 28.913 & 13,4 & 14.608 & 6,8 & 215.346 \\
\hline Lago Azul $^{1}$ & 44.488 & 37,3 & 25.722 & 21,6 & 34.694 & 29,1 & 12.800 & 10,7 & 1.585 & 1,3 & 119.289 \\
\hline Nascente do Belém & 124 & 0,8 & 1.741 & 11,0 & 10.408 & 65,6 & 1.278 & 8,1 & 2.325 & 14,6 & 15.876 \\
\hline Iguaçu-Náutico $^{2}$ & 547.262 & 45,5 & 409.085 & 34,0 & 175.185 & 14,6 & 65.161 & 5,4 & 7.286 & 0,6 & 1.203 .979 \\
\hline Passaúna ${ }^{2}$ & 144.6843 & 91,8 & 42.017 & 2,7 & 72.120 & 4,6 & 15.064 & 1,0 & 0 & 0,0 & 1.576 .044 \\
\hline Passeio Publico $^{1}$ & 15.437 & 17,0 & 2.876 & 3,2 & 29.742 & 32,8 & 27.874 & 30,7 & 14.863 & 16,4 & 90.792 \\
\hline Iguaçu - Peladeiro $^{1}$ & 43.774 & 13,9 & 150.773 & 47,9 & 59.354 & 18,8 & 47.426 & 15,1 & 13.591 & 4,3 & 314.918 \\
\hline São Lourenço ${ }^{2}$ & 43.668 & 18,3 & 41.705 & 17,5 & 115.431 & 48,5 & 28.716 & 12,1 & 8.579 & 3,6 & 238.099 \\
\hline Tanguá $^{1}$ & 29.796 & 13,0 & 48.959 & 21,4 & 110.062 & 48,2 & 30.591 & 13,4 & 9.002 & 3,9 & 228.410 \\
\hline Tingui $^{2}$ & 103.444 & 23,7 & 121.446 & 27,8 & 155.722 & 35,7 & 34.092 & 7,8 & 21.430 & 4,9 & 436.134 \\
\hline Tulio Vargas ${ }^{1}$ & 576 & 1,0 & 14.054 & 25,1 & 33.334 & 59,5 & 3.777 & 6,7 & 4.257 & 7,6 & 55.998 \\
\hline Média & 132.562 & 18,4 & 78.209 & 25,4 & 98.275 & 38,7 & 30.212 & 12,0 & 9.370 & 5,6 & 348.628 \\
\hline
\end{tabular}

1 Parques onde a capivara não foi registrada em todos os censos ou apenas em estudos anteriores (ALMEIDA, et al., 2013a; ALMEIDA $e t$ al., 2013b).

${ }^{2}$ Parques onde a capivara foi registrada nos quatro censos.

FLORESTA, Curitiba, PR, v. 47, n. 3, p. 257 - 267, jul. / set. 2017.

Tonetti, A. M. et al.

ISSN eletrônico 1982-4688

DOI: $10.5380 /$ rf.v47i1.49821 
A comparação entre os componentes floresta, gramado, água, infraestrutura e rua nas áreas com e sem capivara indicou diferenças significativas entre água e floresta (Tabela 2). Esse resultado indica que a capivara está nas áreas verdes que apresentam maior superfície coberta por água e floresta.

Tabela 2. Comparação entre os componentes da paisagem presentes no interior dos bosques e parques.

Table 2. Comparison between the landscape components present inside the green áreas.

\begin{tabular}{lcc|ccc}
\hline $\begin{array}{l}\text { Componentes da } \\
\text { paisagem }\end{array}$ & $\begin{array}{c}\text { Área verde com } \\
\text { capivara }\end{array}$ & $\begin{array}{c}\text { Área verde sem } \\
\text { capivara }\end{array}$ & \multicolumn{2}{c}{ Teste Qui-quadrado } \\
\cline { 2 - 6 } & $\boldsymbol{\%}$ & $\boldsymbol{\%}$ & $\boldsymbol{\chi}^{\mathbf{2}}$ & $\mathbf{p}$ & Resultado \\
\hline Água & 26,5 & 3,9 & 16,883 & $<0,05$ & Diferente \\
Gramado & 23,3 & 20,7 & 0,154 & $>0,05$ & Semelhante \\
Floresta & 33,5 & 56,6 & 5,929 & $<0,05$ & Diferente \\
Infraestrutura & 12,3 & 10,6 & 0,126 & $>0,05$ & Semelhante \\
Rua & 4,4 & 8,1 & 1,095 & $>0,05$ & Semelhante \\
\hline
\end{tabular}

Verifica-se que nas áreas verdes com capivara os componentes com maiores percentagens são água, gramado e floresta $(26,5 \%, 23,3 \%$ e $33,5 \%$ respectivamente), sendo essas proporções estatisticamente semelhantes $\left(\chi^{2}=1,957 ; \mathrm{gl}=2 ; \mathrm{p}>5 \%\right)$. Desta forma, água, gramado e floresta são as coberturas do solo características das áreas verdes de Curitiba onde as capivaras estão presentes.

Nas áreas sem capivara os componentes água, gramado e floresta estão em proporções desiguais (3,9\%, $20,7 \%$ e $56,6 \%$ respectivamente), evidenciando um predomínio de floresta nessas paisagens. Observa-se também, que a quantidade de água nesses ambientes, além de ser a menor entre os componentes da paisagem (3,9\%), é 6,8 vezes menor que a quantidade presente nas áreas verdes com capivara (26,5\%).

A análise estatística demostrou não existir diferença significativa entre o componente infraestrutura nas paisagens com e sem capivara. Logo, os elementos construídos parecem não influenciar a presença ou ausência da espécie nas áreas verdes da cidade.

No que se refere ao tamanho dos bosques e parques estudados, o teste U indicou que o tamanho da área verde influencia na presença do mamífero $(p=0,0007068)$. Devido a isso a espécie foi registrada apenas em parques, onde a área é maior (área média: 35,0 hectares) que a dos bosques (área média: 5,7 ha). Por essa razão também, foi verificada a presença constante da capivara (todas as fases de campo) nos parques com as maiores áreas, como o Parque Barigui (151,4 ha), o Parque Náutico (120,4 ha) e o Parque Passaúna (157,6 ha).

Com relação aos componentes ilha e rio, de acordo com o teste exato de Fischer, ambos estão relacionados a presença de capivaras nas áreas verdes de Curitiba ( $\mathrm{p}$-valor de ilha $=0,003421$; $\mathrm{p}$-valor de rio $=0,000981$ ). Assim, os ambientes que possuem ilha ou rio são as áreas mais favoráveis à presença da espécie na cidade.

Por conta disso, as capivaras estão em nove $(81,8 \%)$ das 11 áreas verdes que possuem ilha e em 11 $(84,6 \%)$ das 13 áreas com rio. As exceções das áreas com rio em que não foi verificada a ocorrência da capivara são o Bosque João Paulo II e o Bosque Irmã Clementina. A ausência do mamífero nesses dois bosques está relacionada ao tamanho pequeno das áreas (6,6 e 2,7 ha respectivamente), já que esse é um componente que interfere na ocorrência da espécie. Quanto ao Bosque João Paulo II, além de ser uma área fora dos padrões de tamanho, o leito concretado do rio Belém que margeia esse bosque dificulta o acesso da área, à medida que a parede alta e reta impede a escalada do animal.

Sobre o componente água, apesar de estar presente de forma constante nos bosques/parques da cidade, a quantidade $\left(\mathrm{m}^{2}\right)$ difere entre as áreas verdes estudadas. Ao associar a água com os parques onde há maiores populações de capivara, percebe-se que os parques que abrigam grupos maiores e mais agregados (Parque Barigui e Parque Cambuí), também apresentam menores proporções de água. Contrariamente, o parque com grupos menores e mais distantes (Parque Iguaçu-Náutico) possui maior proporção de água (Tabela 3).

Tabela 3. Áreas verdes onde foram registradas as maiores populações de capivara.

Table 3. Green areas where the largest populations of capybara were recorded.

\begin{tabular}{lcc}
\hline Parque & $\mathbf{N}^{\circ}$ máximo de capivara por grupo & Área de Água (ha) \\
\hline Barigui & $18-26$ & 18,8 \\
Cambuí & $16-28$ & 13,5 \\
Iguaçu-Náutico & $10-20$ & 45,5 \\
\hline
\end{tabular}


Nas análises do entorno, as médias dos componentes indicaram que a paisagem do entorno é composta por $1,2 \%$ de água, $34,7 \%$ de vegetação e $64,1 \%$ de área impermeável (Tabela 4). Logo, a área impermeável é o componente que predomina no entorno dos ambientes estudados.

Tabela 4. Área e porcentagem das variáveis estudadas no entorno dos bosques e parques de Curitiba (PR).

Table 4. Area and percentage of variables surrounding the green areas of Curitiba (PR).

\begin{tabular}{|c|c|c|c|c|c|c|c|}
\hline \multirow{2}{*}{ Área Verde } & \multicolumn{2}{|c|}{ Água } & \multicolumn{2}{|c|}{ Vegetação } & \multicolumn{2}{|c|}{ Área impermeável } & \multirow{2}{*}{$\begin{array}{c}\text { Total } \\
\mathbf{m}^{2} \\
\end{array}$} \\
\hline & $\mathrm{m}^{2}$ & $\%$ & $\mathbf{m}^{2}$ & $\%$ & $\mathbf{m}^{2}$ & $\%$ & \\
\hline \multicolumn{8}{|l|}{ Bosque } \\
\hline Alemão & 0 & 0,0 & 6.720 & 2,7 & 244.945 & 97,3 & 251.665 \\
\hline De Portugal & 468 & 0,2 & 12.969 & 5,7 & 215.654 & 94,1 & 229.091 \\
\hline Do Pilarzinho & 335 & 0,1 & 119.627 & 48,6 & 125.967 & 51,2 & 245.929 \\
\hline Do Trabalhador & 0 & 0,0 & 157.040 & 48,0 & 169.870 & 52,0 & 326.910 \\
\hline Irmã Clementina & 2.194 & 1,1 & 49.818 & 25,9 & 140.291 & 73,0 & 192.303 \\
\hline João Paulo II & 1.791 & 0,7 & 55.993 & 22,8 & 187.771 & 76,5 & 245.555 \\
\hline Reinhard Maack & 933 & 0,3 & 22.195 & 8,1 & 249.880 & 91,5 & 273.008 \\
\hline São Nicolau & 671 & 0,4 & 16.469 & 9,6 & 154.610 & 90,0 & 171.750 \\
\hline Zaninelli-Unilivre & 0 & 0,0 & 80.968 & 34,3 & 154.991 & 65,7 & 235.959 \\
\hline Média & 710 & $\mathbf{0 , 3}$ & 57.978 & 22,9 & 182.664 & 77,0 & 241.352 \\
\hline \multicolumn{8}{|l|}{ Parque } \\
\hline Atuba & 1.350 & 0,3 & 274.716 & 66,4 & 137.758 & 33,3 & 413.824 \\
\hline Barigui & 3.713 & 0,4 & 216.000 & 20,6 & 830.914 & 79,1 & 1.050 .627 \\
\hline Barreirinha & 1.026 & 0,3 & 181.516 & 59,0 & 125.065 & 40,7 & 307.607 \\
\hline Caiuá & .0 & 0,0 & 82.315 & 24,3 & 255.946 & 75,7 & 338.261 \\
\hline Cambuí & 10.462 & 2,5 & 72.025 & 17,5 & 329.811 & 80,0 & 412.298 \\
\hline Cent. Imigr. Japonesa & 29.697 & 6,0 & 284.168 & 57,9 & 177.251 & 36,1 & 491.116 \\
\hline Das Pedreiras & 0 & 0,0 & 82.072 & 27,6 & 214.787 & 72,4 & 296.859 \\
\hline Diadema & 0 & 0,0 & 112.488 & 26,5 & 312.186 & 73,5 & 424.674 \\
\hline Dos Tropeiros & 4.606 & 1,1 & 230.098 & 56,7 & 171.411 & 42,2 & 406.115 \\
\hline Iberê de Mattos & 1.985 & 0,5 & 133.615 & 34,4 & 253.282 & 65,1 & 388.882 \\
\hline Italiano & 4.621 & 1,3 & 119.615 & 34,9 & 218.092 & 63,7 & 342.328 \\
\hline Jardim Botânico & 0 & 0,0 & 48.914 & 12,8 & 332.268 & 87,2 & 381.182 \\
\hline Lago Azul & 11.424 & 3,3 & 283.733 & 81,2 & 54.229 & 15,5 & 349.386 \\
\hline Nascente do Belém & 457 & 0,3 & 47.344 & 30,6 & 107.094 & 69,1 & 154.895 \\
\hline Iguaçu-Náutico & 30.109 & 3,2 & 552.569 & 58,1 & 367.826 & 38,7 & 950.504 \\
\hline Passaúna & 127.167 & 7,2 & 1.455 .863 & 82,9 & 172.991 & 9,9 & 1.756 .021 \\
\hline Passeio Publico & 0 & 0,0 & 0 & 0,0 & 269.803 & 100,0 & 269.803 \\
\hline Iguaçu - Peladeiro & 24.647 & 5,8 & 189.372 & 44,9 & 207.690 & 49,2 & 421.709 \\
\hline São Lourenço & 1.128 & 0,2 & 135.036 & 28,9 & 331.875 & 70,9 & 468.039 \\
\hline Tanguá & 2.315 & 0,5 & 244.143 & 50,7 & 234.710 & 48,8 & 481.168 \\
\hline Tingui & 2.531 & 0,3 & 381.901 & 43,0 & 503.727 & 56,7 & 888.159 \\
\hline Tulio Vargas & 264 & 0,1 & 29.407 & 11,8 & 219.405 & 88,1 & 249.076 \\
\hline Média & 11.705 & 1,5 & 234.405 & 39,6 & 264.915 & 58,9 & 511.024 \\
\hline
\end{tabular}

A comparação entre os componentes água, vegetação e infraestrutura nas áreas com e sem capivaras, não indicou diferenças significativas (Tabela 5). Portanto, a quantidade desses componentes no entorno não está relacionada à presença da espécie nas áreas verdes de Curitiba.

Tabela 5. Comparação entre os componentes da paisagem presentes no entorno dos bosques e parques amostrados.

Table 5. Comparison between the landscape components present in the surrounding green areas.

\begin{tabular}{lcc|ccc}
\hline $\begin{array}{l}\text { Componentes } \\
\text { da paisagem }\end{array}$ & $\begin{array}{c}\text { Área verde com } \\
\text { capivara }\end{array}$ & $\begin{array}{c}\text { Área verde sem } \\
\text { capivara }\end{array}$ & \multicolumn{2}{c}{ Teste Qui-quadrado } \\
\cline { 2 - 6 } & $\boldsymbol{\%}$ & $\boldsymbol{\%}$ & $\chi^{\mathbf{2}}$ & $\mathbf{p}$ & Resultado \\
\hline Água & 2,1 & 0,4 & 1,156 & $>0,05$ & Semelhante \\
Vegetação & 42,3 & 28,5 & 2,690 & $>0,05$ & Semelhante \\
Área impermeável & 55,6 & 71,1 & 1,896 & $>0,05$ & Semelhante \\
\hline
\end{tabular}

FLORESTA, Curitiba, PR, v. 47, n. 3, p. 257 - 267, jul. / set. 2017

Tonetti, A. M. et al.

ISSN eletrônico 1982-4688

DOI: $10.5380 /$ rf.v47i1.49821 
Apesar do teste estatístico ter indicado não haver relação entre a quantidade dos componentes e a ocorrência da capivara, verifica-se que dos 1,2\% de água presentes no entorno, $84 \%$ está em parques nos quais as capivaras estão presentes e $16 \%$ onde a espécie está ausente. Estatisticamente, essa diferença indica que o componente água predomina nas áreas verdes com capivara, $\left(\chi^{2}=46,240, \mathrm{gl}=1 ; \mathrm{p}<5 \%\right)$. Logo, as capivaras de Curitiba se encontram em áreas verdes cujo entorno possui água. Um entorno com essa característica confere à espécie alternativas de refúgio (lago) e conexão com hábitats próximos (rios).

Ao analisar apenas as áreas com registro da espécie (parques), observou-se que em alguns parques a capivara se manteve permanente (presença nos quatro períodos de monitoramento - agosto de 2013 a junho de 2015) e em outros a espécies esteve temporariamente (ausência em alguns períodos ou presença apenas em estudos anteriores) (Tabela 1, Figura 1).

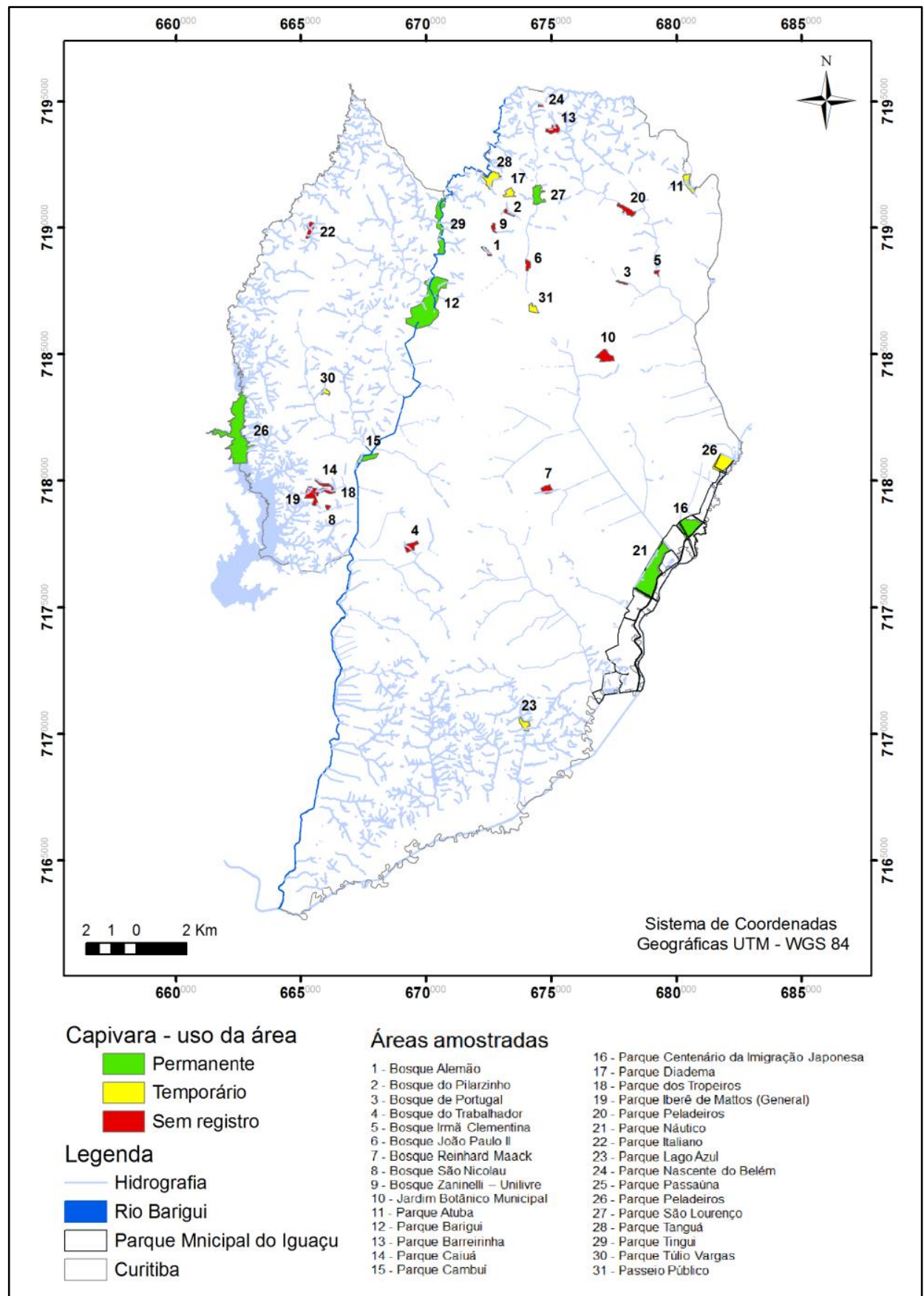

Figura 1. Capivaras registradas entre 2008 e 2015.

Figure 1. Capybaras recorded between 2008 and 2015. 
Existem diferenças nas paisagens que estão relacionadas à forma como a espécie utiliza os parques. As áreas de uso permanente são 5,2 vezes maiores que a de uso temporário. O componente água predomina na paisagem das áreas de uso permanente $(38,5 \%)$, enquanto que nas áreas de uso temporário esse representa apenas $14,6 \%$. Os componentes gramado e floresta se encontram em maiores proporções nas áreas de uso temporário. Já os componentes ilha e rio estão em todas as áreas de uso permanente (Tabela 6).

Tabela 6. Componentes da paisagem no interior das áreas de ocorrência de Hydrochoerus hydrochaeris. Table 6. Landscape components inside the occurrence areas of Hydrochoerus hydrochaeris.

\begin{tabular}{|c|c|c|c|c|c|c|c|c|}
\hline \multirow[b]{2}{*}{ Uso da área } & \multicolumn{5}{|c|}{ Média $(\%) \pm \mathrm{DP}$} & \multirow{2}{*}{$\begin{array}{c}\text { Média }\left(\mathrm{m}^{2}\right) \pm \mathrm{DP} \\
\text { Área total }\end{array}$} & \multicolumn{2}{|c|}{ Presença (\%) } \\
\hline & Água & Gramado & Floresta & $\begin{array}{c}\text { Infraestru- } \\
\text { tura }\end{array}$ & Rua & & Ilha & Rio \\
\hline Permanente & $38,5 \pm 29$ & $21,9 \pm 10$ & $29,3 \pm 19$ & $7,7 \pm 4$ & $2,7 \pm 2$ & $797.000 \pm 610.000$ & 100 & 100 \\
\hline Temporário & $14,6 \pm 11$ & $24,7 \pm 15$ & $37,7 \pm 13$ & $16,9 \pm 10$ & $6,1 \pm 5$ & $152.000 \pm 90.000$ & 28,6 & 57,1 \\
\hline
\end{tabular}

Nas áreas de uso permanente, também pode ser verificado, que os componentes água $(38,5 \%)$, gramado $(21,9 \%)$ e floresta $(29,3 \%)$ se encontram em maiores percentagens que infraestrutura $(7,7 \%)$ e rua $(2,7 \%)$. Os componentes água, gramado e floresta além de predominarem na paisagem são estatisticamente semelhantes $\left(\chi^{2}\right.$ $=4,601 ; \mathrm{gl}=2 ; \mathrm{p}>5 \%$ ), revelando uma distribuição homogenia na paisagem.

No que se refere à análise do entorno, apesar das áreas de uso permanente possuir maior quantidade de água e vegetação e menor quantidade de área impermeável que as áreas de uso temporário (Tabela 7), essas diferenças não foram significativas. As proporções dos componentes água, gramado e floresta são estatisticamente equivalentes (ÁGUA: $\chi^{2}=0,466 ; \mathrm{gl}=1 ; \mathrm{p}>5 \%$ - GRAMADO: $\chi^{2}=0,153$; gl $=1 ; \mathrm{p}>5 \%$ FLORESTA: $\left.\chi^{2}=0,233 ; \mathrm{gl}=1 ; \mathrm{p}>5 \%\right)$. Portanto, as características do entorno não determinam a forma de uso das áreas verdes de Curitiba (temporário ou permanente) pelas capivaras.

Tabela 7. Componentes da paisagem no entorno das áreas de ocorrência de Hydrochoerus hydrochaeris. Table 7. Landscape components in the surroundings of the occurrence areas of Hydrochoerus hydrochaeris.

\begin{tabular}{lccc}
\hline \multirow{2}{*}{ Uso da área } & \multicolumn{3}{c}{ Média (\%) \pm DP } \\
\cline { 2 - 4 } & Água & Vegetação & Área impermeável \\
\hline Permanente & $2,8 \pm 3$ & $44,1 \pm 23,7$ & $53,1 \pm 26,1$ \\
Temporário & $1,4 \pm 2$ & $40,4 \pm 29$ & $58,2 \pm 30$ \\
\hline
\end{tabular}

\section{DISCUSSÃO}

As 31 áreas verdes estudadas são potenciais hábitats para a capivara, pois todas apresentam em suas paisagens componentes essenciais à sobrevivência da espécie (água, floresta e vegetação rasteira - gramado) (MOREIRA, et al., 2013). Entretanto, o mamífero foi registrado em apenas 14 dessas áreas (45,2\%). Isso se deve a diferenças paisagísticas intrínsecas que interfere na escolha de um ambiente em detrimento de outro.

As diferenças verificadas entre as áreas com e sem capivaras, evidenciam que a ocorrência da capivara nas áreas verdes da cidade de Curitiba está relaciona as maiores percentagens dos componentes água, floresta e gramado. Essa mesma associação já foi registrada por Almeida e Biondi (2011), os quais verificaram que em área onde grupos de capivaras permanecem os elementos naturais lago, gramado e floresta estão em maiores proporções e melhor distribuídos na paisagem.

A água é o componente mais importante entre os recursos exigidos pela espécie, isso se deve a utilização dessa como local de reprodução, termorregulação, alimentação, refúgio contra predadores e caçadores e, no caso de rios, fundamental como corredor ecológico (GONÇALVES; OLIVEIRA, 2011; ALMEIDA et al., 2013c; BYRNE et al., 2015). Além disso, em regiões onde há variações sazonais, a água também atua na composição e dinâmica populacional (CORRIALE et al., 2013). Por essas razões esse componente da paisagem é o que apresentou maior percentagem nas áreas verdes com capivara.

A importância do gramado está relacionada à dieta, segundo Tonetti e Biondi (2015), em ambiente urbano a capivara se alimenta preferencialmente de vegetação rasteira presente em áreas gramadas. A disponibilidade de alimento interfere na ecologia da espécie, principalmente em regiões onde há variações climáticas bem marcadas (CORRIALE et al., 2013; HERRERA, 2013). Contudo, nos parques de Curitiba à oferta constante de alimento, devido às características climáticas da cidade, favorece o crescimento populacional desse herbívoro. Em consequência disso, a espécies está presente nas áreas com maior quantidade de gramado.

A floresta é outro componente bastante utilizado pela espécie, tanto em ambiente mais preservado quanto em hábitat urbano. Nela, as capivaras se refugiam de predadores, parem seus filhotes, regulam a temperatura corporal e se alimentam de folhas e brotos (HERRERA, 2013; ALMEIDA et al., 2012; TONETTI;

FLORESTA, Curitiba, PR, v. 47, n. 3, p. 257 - 267, jul. / set. 2017.

Tonetti, A. M. et al.

ISSN eletrônico 1982-4688

DOI: $10.5380 /$ rf.v47i1.49821 
BIONDI, 2015). Por conta disso, era esperado que esse componente também apresentasse maiores percentagens nas áreas verdes onde a capivara está presente.

Por mais que seja estranho ter sido observado maior quantidade (área) de elementos construídos (infraestrutura) nas paisagens escolhidas pelas capivaras, a infraestrutura dos bosques/parques parece conferir proteção à espécie. As quadras esportivas e recreativas, trilhas, ciclovias, pista de caminhada e de corrida presentes nos bosque/parque da cidade atraem as pessoas, que utilizam essas áreas como lazer, recreação, práticas esportivas e, sobretudo, contato com a natureza (PETROSKI et al., 2009; TONETTI et al., 2016). Essa presença humana constante atua como fator protetivo inibindo a pratica da caça furtiva de capivara, uma vez que a imagem do caçador e de seu impacto sob a fauna silvestre é vista pela sociedade moderna como algo negativo (FERNANDES-FERREIRA; ALVES, 2014).

Sobre o componente rua, por mais que as áreas verdes com e sem capivara possuam percentagens semelhantes, esperava-se que esse componente fosse predominante nas áreas sem capivara. Pois, ruas e estradas conferem grande impacto sob a fauna silvestre, aumentando o risco de morte por atropelamento e dificultando a movimentação da espécie entre áreas vizinhas (LANG; BLASCHKE, 2009). Independentemente disso, o resultado indica que o componente rua não influencia ou interfere na escolha das áreas verdes de Curitiba pela espécie. Isso, provavelmente, ocorre porque as capivaras se tornaram mais tolerantes aos efeitos causados pelas ruas que margeiam e fragmentam os parques da cidade ou, ainda, que elas utilizam os rios para se deslocarem entre áreas vizinhas, evitando assim a travessia pelas ruas ou estradas.

Os parques públicos de Curitiba mostram-se adequados quanto ao tamanho (154.895 a $\left.1.756 .021 \mathrm{~m}^{2}\right)$, pois apesar da área de vida da capivara ser variável, já foram registrados grupos vivendo em ambientes de 110.000 a $280.000 \mathrm{~m}^{2}$ (CORRIALE et al., 2013) e entre 100.000 a $2.000 .000 \mathrm{~m}^{2}$ (HERRERA et al., 2011).

Os componentes ilha e rio também estão relacionados à presença de Hydrochoerus hydrochaeris nas áreas amostradas. Sobre a ilha, Gonçalves e Oliveira (2011) relatam que rochas em rios profundos são utilizadas por capivaras para se protegerem de caçadores em Santiago (RS). Como nos rios de Curitiba não é comum a presença de rochas, a espécie se abrigam nas ilhas presentes nas áreas verdes públicas da cidade (ALMEIDA et al., 2013c). No que se refere ao rio, além de proteção contra predadores e caçadores, atua como corredor ecológico (BYRNE et al., 2015). Assim, a ocorrência dos dois componentes (ilha e rio) numa mesma área, confere proteção e fluxo da espécie entre áreas próximas, torando-se hábitats altamente atrativos para as capivaras em um contexto urbano. Devido a isso, as áreas onde existe simultaneamente rio e ilha são as mesmas onde foi registrada a permanência de grupo(s) de capivara (parques: Barigui, Cambuí, Centenário da Imigração Japonesa, Iguaçu-Náutico, São Lourenço e Tingui). A constante presença de grupos com filhotes indica que a área além de disponibilizar recursos, dá suporte para que a população reproduza, conferindo proteção contra predação e caça e garantindo o fluxo genético entre populações vizinhas.

Com relação ao componente água dentro das áreas amostradas, notou-se que a composição e distribuição dessas populações parecem ser influenciadas pela disponibilidade do componente água na paisagem. Isso corrobora com Maldonado-Chaparro e Palomino (2010), que observaram grupos maiores e mais próximos durante a estiagem e menores e mais dispersos durante as inundações.

Além dessas características o entorno também parece estar relacionado à ocorrência do mamífero. As maiores proporções de vegetação e água atuam na ampliação da área do parque, pois a vegetação disponibiliza mais opção de alimento e proteção à espécie e a água confere alternativas de refúgio (lago) e conexão com hábitats próximos (rios).

Sobre a área impermeável, esperava-se que esse componente estivesse presente em maior proporção nos entornos de áreas onde a espécie não ocorre, porém se encontra em proporções semelhantes nas áreas com e sem capivara (Tabela 5). Desta forma, a área impermeável, que no entorno é representada por componentes construídos (residências, escolas, empresas, etc.) e pistas pavimentadas, parece não influenciar na escolha de um parque como hábitat.

De maneira geral, as características ambientais comuns às áreas verdes públicas de Curitiba onde ocorre Hydrochoerus hydrochaeris são: parques com maior área, com ilha e rio; com quantidades maiores de água, floresta, gramado e infraestrutura; e com entornos com maiores quantidades de vegetação e água.

A fixação da espécie nas áreas de uso permanente se deve a maior proporção de água e a presença de ilha e rio na paisagem (componentes que conferem proteção à espécie), mas também ao maior tamanho de área e a menor percentagem do componente área impermeável. Áreas maiores (com recursos suficientes) suportam populações maiores (ALMEIDA; BIONDI, 2011; CORRIALE et al., 2013) e menores quantidades de pavimentação reduzem o risco de morte por atropelamento (LANG; BLASCHKE, 2009). Desta forma, as áreas mais vantajosas para a espécie (de melhor qualidade) são aquelas que as capivaras escolheram para permanecer. Almeida e Biondi (2011) também verificaram aglomeração e permanência de capivaras em hábitat de melhor qualidade.

Contrariamente, as áreas de uso temporário são menores, a quantidade de água é menor e nem todas possuem rio ou ilha, entretanto apresentam quantidades maiores de alimento (gramado e floresta). Assim, provavelmente, as capivaras utilizam esses parques como fonte nutricional e abrigo transitório, porém não se 
fixam devido às condições de pouca proteção. Logo, esses podem estar atuando como locais de passagem (stepping stones - trampolins ecológicos), que segundo Degraaf e Miller (1996) são fragmentos menores utilizados pelas espécies para chegar a fragmentos de hábitat maiores.

A localização também é outro fator que pode induzir a utilização temporária. Nos parques Atuba, Tanguá e Iguaçu-Peladeiro as capivaras foram registradas poucas vezes (uso temporário). Isso provavelmente ocorreu por serem áreas localizadas na fronteira com municípios vizinhos, já que ambientes com essas características sofrem mais com a pressão cinegética devido a dificuldades de fiscalização (PINHEIRO, 2014).

Percebe-se, assim, que as capivaras usam de forma permanente os maiores parques da cidade, onde a água é o componente mais abundante, e os entornos apresentam predomínio de vegetação e presença de água. Portanto, essas são as áreas que dão suporte para que populações de capivaras se estabeleçam e reproduzam.

Além das características individuais, observando espacialmente cada área (Figura 1) verifica-se que alguns parques funcionam como fragmentos de hábitat, em uma matriz urbanizada, conectados por rios (LANG; BLASCHKE, 2009). Um bom exemplo disso é o parque linear formado pelos parques Tanguá, Tingui, Barigui e Cambuí, que formam um cinturão verde ao longo do Rio Barigui. O registro de capivara nesses parques e em regiões intermediárias evidencia o papel ecológico e a importância desse rio para a espécie (ALMEIDA et al., 2013a).

Nos parques Iguaçu-Peladeiro, Centenário da Imigração Japonesa e Iguaçu-Náutico a presença da capivara é garantida não apenas pelas características intrínsecas (área e entorno), mas também pela conectividade (Rio Iguaçu) e adjacências. Esses parques estão mergulhados em um mosaico complexo de vegetações que inclui várzeas e matas ciliares ao longo do Rio Iguaçu, presentes no Parque Municipal do Iguaçu e na Reserva Biológica do Cambuí (Unidade de Conservação adjacente) (VALLEJOS et al., 2011).

Observa-se que a rede hídrica distribuída por toda cidade exerce uma importante função ecológica que influencia a ecologia de Hydrochoerus hydrochaeris, resultando na ocorrência em determinadas áreas verdes e ausência em outras. O papel da conectividade é tão relevante que Byrne et al. (2015), encontraram uma relação altamente significativa entre distância genética e distância de rio como corredor, indicando que o fluxo gênico é garantido pela estrutura espacial das redes fluviais.

Nessa composição da paisagem, os parques de uso temporário são fundamentais para a movimentação da espécie na cidade, à medida que podem funcionar como trampolins ecológicos que auxiliam o mamífero a chegar em hábitats onde os recursos são mais abundantes, os parques de uso permanente.

$\mathrm{O}$ estabelecimento da espécie nos parques de Curitiba deve-se tanto às características ambientais que esses disponibilizam quanto ao arranjo espacial e conectividade desses na paisagem. Aliado a isso, existe a ausência de predadores naturais (onça e jacaré) e a proteção jurídica da fauna silvestre (Lei de proteção à fauna n. ${ }^{\circ}$ 5197/67), que tornam essas áreas hábitats favoráveis à capivara. Principalmente, frente à realidade atual de perda de hábitat e pressão cinegética.

\section{CONCLUSÕES}

- $\quad$ O estudo das paisagens dos bosques e parques de Curitiba permitiu identificar peculiaridades nas paisagens das áreas onde a capivara foi registrada, que estão diretamente relacionadas à disponibilidade de recursos e a necessidade de proteção cinegética. Além disso, deu indícios que a estrutura da paisagem entre os parques, como a conectividade por rios e a presença de áreas de preservação nos arredores, são fatores importantes que auxiliam na fixação e movimentação da espécie nas áreas verdes de Curitiba.

- O entendimento dessa relação animal-ambiente em grandes centros urbanos, principalmente na cidade de Curitiba, é essencial para a elaboração de planos estratégicos de conservação e manejo tanto de Hydrochoerus hydrochaeris quanto da fauna silvestre urbana como um todo.

\section{AGRADECIMENTOS}

À Fundação Coordenação de Aperfeiçoamento de Pessoal de Nível Superior (CAPES), pelo auxílio financeiro, ao Museu de História Natural da Prefeitura Municipal de Curitiba pela assistência e apoio na coleta de dados zoológicos, ao Laboratório de Paisagismo da Universidade Federal do Paraná pelo fornecimento da imagem de satélite e à SMMA e ao IPPUC pelo fornecimento dos dados vetoriais.

\section{REFERÊNCIAS}

ALMEIDA, A. M. R.; BIONDI, D. A study of the landscape and the occurence of Hydrochoerus hydrochaeris at Tinugi Municipa Park in Curitiba, state of Parana. Amazonian Journal of Agricultural and Environmental Sciences, Taubaté, v. 54, n. 3, p. 280-289, 2011.

FLORESTA, Curitiba, PR, v. 47, n. 3, p. 257 - 267, jul. / set. 2017. 
ALMEIDA, A. M. R; BIONDI, D.; MONTEIRO FILHO, E. L. A. Comportamento de capivaras em área verde urbana no município de Curitiba, PR. Revista Biociências, Taubaté, v. 18, n. 1, p. 24-31, 2012.

ALMEIDA, A. M. R; BIONDI, D.; MONTEIRO FILHO, E. L. A. Dinâmica e biologia de uma população de capivaras em ambiente. Ciência e Natura, Santa Maria, v. 35, n. 2, p. 54-64, $2013 \mathrm{a}$.

ALMEIDA, A. M. R.; ARZUA, M.; TRINDADE, P. W. S.; SILVA JUNIOR, A. Capivaras (Hydrochoerus hydrochaeris, Linnaeus, 1766) (Mammalia: Rodentia) em áreas verdes do município de Curitiba (PR). Estudos de Biologia, Curitiba, v. 35, n. 84, p. 9-16, 2013 b.

ALMEIDA, A. M. R.; LELAL, L.; BIONDI, D.; MARTINI, A.; LIMA-NETO, E. M. Caracterização microclimática do Parque Municipal Tingui, Curitiba-PR e a ocorrência de capivaras (Hydrochoerus hydrochaeris, Linnaeus, 1766). Revista Brasileira de Arborização Urbana, Piracicaba, v. 8, n. 2, p. 46-57, 2013c.

ALMEIDA, A. M. R.; GRISE, M. M.; BIONDI, D.; SILVA-FILHO, D. F. Estudo de hábitat urbano de mamífero nativo Hydrochoerus hydrochaeris (Linnaeus, 1766) (capivara) com uso de sensoriamento remoto, Curitiba, Paraná, Brasil. Ciência e Natura, Santa Maria, v. 36, n. 3, p. 277-286, 2014.

BOLÓS, M. Manual de ciencia del paisaje: teoría, métodos e aplicaciones. Barcelona: MASSON, 1992.

BYRNE, M. S.; QUINTANA, R. D.; BOLKOVIC, M. L.; CASSINI, M. H.; TÚNEZ, J. I. The role of river drainages in shaping the genetic structure of capybara populations. Genetica, Berlin, v. 143, n. 6, p. 645-656, 2015.

CORRIALE, M. J.; MUSCHETTO, E.; HERRERA, E. A. Influence of group sizes and food resources in homerange sizes of capybaras from Argentina. Journal of Mammalogy, United Kingdom, v. 94, n. 1, 2013.

DEGRAAF, R. M.; MILLER, R. I. Conservation of faunal diversity in forested landscapes. London: Chapman \& Hall, 1996. 633p.

FERNANDES-FERREIRA, H.; ALVES, R. R. N. Legislação e mídia envolvendo a caça de animias silvestres no Brasil: uma perspectiva histórica e socioambiental. Gaia Scientia, João Pessoa, v. 8, n. 1, p. 01-07, 2014.

GRISE, M. M; BIONDI, D.; ARAKI, H. A floresta urbana da cidade de Curitiba, PR. Floresta, Curitiba, v. 46, n. 4, p. 425-438, 2016.

GONÇALVES, A. S.; OLIVIERA, D. G. The influence of river depth and length of riparian vegetation on the presence of capybaras (Hydrochoerus hydrochaeris Mones \& Ojasti, 1986). Ciência e Natura, Santa Maria, v. 33, n. 1, p. 33-42, 2011.

HERRERA, A. E.; SALAS, V.; CANGON, E. R.; CORRIALE, M. J.; TANG-MARTÍNEZ, Z. Capybara social structure and dispersal patterns: variations on a theme. Journal of Mammalogy, United Kingdom, v. 92, n. 1, p. 12-20, 2011.

HERRERA, E. Capybara Social Behavior and use of Space: Patterns and Processes. In: MOREIRA, J. R.; FERRAZ.K. M. P. M. B.; HERRERA, E. A.; MACDONALD, D. W. Capybara: biology, use and conservation of an exceptional neotropical species, New York: Ed Springer, 2013, p. 195-210.

LANG, S.; BLASCHKE, T. Análise da paisagem com SIG. São Paulo: Oficina dos Textos, 2009. 424p.

LEHNER. Handbook of ethological methods. New York: Garland STPM Press, 1996. 672p.

MALDONADO-CHAPARRO, A.; PALOMINO, P. S. Seasonal spatial distribution patterns of a capybara (Hydrochoerus hydrochaeris) population in the flooded savannas of Colombia. Mastozoología Neotropical, Mendoza, v. 17, n. 2, p. 287-294, 2010.

METZGER, J. P. Estrutura da paisagem: o uso adequado de métricas. In: CULLEN Jr, L.; RUDRAN, R.; VALLADARES-PADUA, C. Métodos de estudos em biologia da conservação e manejo da vida silvestre. Curitiba: Ed. da UFPR, 2006. p. 423-453.

MOREIRA, J. R.; ALVAREZ, M. R.; TARIFA, T.; PACHECO, V.; TABER, A.; TIRIRA, D. G.; HERRERA,E. A.; FERRAZ, K. M. P. M. B. Taxonomy, Natural History and Distribution of the Capybara. In: MOREIRA, J. R.; FERRAZ, K. M. P. M. B.; HERRERA, E. A.; MACDONALD, D. W. Capybara: biology, use and conservation of an exceptional neotropical species. New York: Springer, 2013. p. 1-37. 
PETROSKI, E. L.; SILVA, D. A. S.; REIS, R. S.; PELEGRINI, A. Estágios de mudança de comportamento e percepção positiva do ambiente para atividade física em usuários de parque urbano. Revista Motricidade, Portugal, v. 5, n. 2, p. 17-31, 2009.

PINHEIRO, G. C. A regularização da caça no Brasil. Revista de Direito Público da Procuradoria-Geral do Município de Londrina, Londrina, v. 3, n. 2, p. 95-115, 2014.

TONETTI, A. M.; BIONDI, D. Dieta de capivara (Hydrochoerus hydrochaeris, Linnaeus, 1766) em ambiente urbano, Parque Municipal Tingui, Curitiba-PR. Acta Veterinaria Brasilica, Mossoró, v. 9, n. 4, p. 316-326, 2015.

TONETTI, A. M.; BIONDI, D.; MOURA LEITE, J. C. Perfil dos usuários de áreas verdes de Curitiba e a sua percepção sobre a capivara (Hydrochoerus hydrochaeris L.). Revista da Sociedade Brasileira de Arborização Urbana, Piracicaba, v. 11, n. 4, p. 47-65, 2016.

VALlEJOS, M. A. V.; LANZER, M.; AURÉliO-SILVA, M.; MEIJER, A. A. R.; CARRANO, E.; STAUBE, F.C. Parque Regional do Iguaçu e adjacências. In: VALENTE, R. M.; SILVA, J. M. C.; STRAUBE, F. C.; NASCIMENTO, J. L. X. Conservação de aves migratórias no Brasil. Belém: Conservação Internacional, 2011, p. 292-297. 